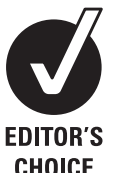

CHOICE
${ }^{1}$ Faculty of Health and Social Sciences, Unitec, Auckland, New Zealand

${ }^{2}$ Faculty of Health and Social Sciences, University of Bedfordshire, Luton, Bedford, UK

${ }^{3}$ Medical School, Swansea University, Swansea, UK

${ }^{4}$ Yorkshire and Humber Deanery, Academic Unit of Anaesthesia, The General Infirmary at Leeds, Leeds, UK

\section{Correspondence to}

Dr Kirsty Forrest, Academic Unit of Anaesthesia, The General Infirmary at Leeds, Great George Street, Leeds LS1 3EX, UK; k.forrest@leeds.ac.uk

Received 28 October 2009 Accepted 9 January 2010

\title{
Using transactional analysis to improve clinical and educational supervision: the Drama and Winner's triangles
}

\author{
Judy McKimm, ${ }^{1,2,3}$ Kirsty Forrest ${ }^{4}$
}

\begin{abstract}
The supervisor-trainee relationship is fundamental in ensuring the best continuing education for all trainees. One of the key skills of supervision is being able to communicate effectively; however, this is sometimes difficult. In this article we explore how two transactional analysis models, the Drama and Winner's triangles, can help supervisors work and communicate more effectively with trainees.

All supervisors will have had a 'heartsink moment' before meeting a known trainee. The models can be used to explain these situations and what exactly is happening to the communication. The models provide methods of breaking free from these frustrating encounters and moving on with the relationship with your trainee. The models also help us understand the ways in which we can easily be pulled into games and offer insight into our own behaviours and relationships, not only with trainees, but also with patients, carers and colleagues. Real life scenarios are used throughout to explain the models.
\end{abstract}

\section{INTRODUCTION}

The supervisor-trainee relationship can be immensely rewarding for both parties. One of the key skills of supervision is being able to communicate effectively and help trainees in their professional and personal development. While many supervisors already offer excellent supervision, supporting trainees is not always easy as trainees are in an often difficult period of transition and uncertainty. Transactional analysis (TA), a model of human interaction and communication, is widely used in clinical, counselling and other contexts. In this article we explore how the TA models of the Drama and Winner's triangles can help supervisors work and communicate more effectively with trainees.

These models are two of many from TA and elsewhere that might be applied to supervision (others include Balint groups, cognitive behavioural therapy (CBT) and systematic narrative). It may be helpful for supervisors to integrate concepts from TA with models they already know and use, providing some ideas for thinking about and structuring supervision. Supervisors interested in developing TA skills and knowledge may wish to learn more through a course or interactive training.

\section{WHAT IS SUPERVISION?}

Supervision can be defined in many ways, but in the medical education context it 'is essentially a conversation between professionals aimed at promoting learning, reflective practice and improving patient safety and the quality of patient care'. In the context of postgraduate medical education, two related types of supervision are defined.

Educational supervision is 'the provision of guidance and feedback on matters of personal, professional and educational development in the context of a trainee's experience of providing safe and appropriate patient care'. ${ }^{2}$ All doctors are required to have educational supervision across their whole training period Clinical supervision is about the everyday supervision of a trainee's performance and teaching onthe-job with developmental conversations, regular feedback and the provision of a rapid response to issues as they arise. ${ }^{3}$ All trainees must have a named clinical supervisor for each post who is required to tailor the level of supervision to the competence, confidence and experience of their trainee.

Supervision therefore supports professional learning and development, but also relates to gate keeping, monitoring, maintaining standards, and improving performance as part of effective clinical governance. ${ }^{4}$ Because the supervisor's role may require working with trainees on complex, sensitive or messy problems, conversations or interactions with trainees may be challenging or difficult. TA can be useful when having conversations with any trainee, but in particular when working with trainees or situations that seem difficult. TA techniques can help supervisors to listen and communicate more effectively and develop relationships with each trainee based on mutual respect and understanding.

\section{TRANSACTIONAL ANALYSIS}

TA has its roots in Freudian psychoanalysis and was developed as a psychological discipline in the late 1950s and 1960s by its founder Eric Berne (a psychiatrist) and others working in the USA. TA's popularity spread worldwide, largely as a consequence of two of Berne's early works: Games people play and What do you say after you say hello? ${ }^{5} 6$ The simple, accessible language that Berne used to explain complex and subtle concepts led to many writers oversimplifying TA concepts and theories, and therefore damaging its reputation as a coherent and dynamic branch of psychotherapy. Since the 1980s, TA theorists and practitioners have worked hard to address the 'pop psychology' image and re-establish TA. It is now widely used in counselling, psychotherapy, training and clinical practice.

The International Transactional Analysis Association, (ITAA) describes TA as 'a theory of personality and a systematic psychotherapy for personal growth and personal change'. It can be used 'in any 
field where there is a need for understanding of individuals, relationships and communication'?

In this article we are not looking at the therapeutic applications of TA, but will focus on how TA may be used in the supervision context, to help supervisors (and trainees) communicate clearly and avoid setting up unproductive confrontations. Stewart and Joines suggest that, although practitioners may be aware of what is going on at the deeper psychological or covert level (and this article aims to raise awareness of this), when using TA in educational or organisational settings, it is more appropriate to stay at the social level, the overt agenda. ${ }^{7}$ This is primarily because psychological protection for individuals is not necessarily available if the covert level is revealed. ${ }^{8}$ Box 1 summarises some key concepts in TA.

We have chosen to focus on two related models from the extensive TA literature to help explain difficult situations arising in supervision: the Drama and Winner's triangles. Underpinning these models are many theoretical concepts which cannot, for reasons of space, be discussed here. The model of the ego state diagram which includes the Parent, Adult and Child ego states is a core concept in TA (figure 1).

At any one time, we are operating in all three ego states, and transactions can take place from each of the parent, adult or child ego-state. In summary:

- The parent ego state (controlling or nurturing parent) incorporates internalised messages from parents and other significant figures from the past-we may find ourselves thinking, behaving or feeling in ways copied from parent or carer figures.

- Parental messages help us to care for others and ourselves and set boundaries, but they can also be negative and over controlling or critical.

- Staying in the adult (behaving, thinking and feeling in the here and now with full adult resources available) may take conscious effort but is the most productive in work situations.

- In most cases, supervision should be on an adult-adult basis.

- Helping the trainee stay in adult can help them make the right decisions.

- When in the child ego state, we return to ways of thinking, behaving or feeling that we used as a child. Sometimes this

\section{Box 1 Key concepts in transactional analysis $(\mathrm{TA})^{79}$}

- Essentially, everyone is $\mathrm{OK}$, however people learn maladaptive behaviours in childhood which can play out in later life.

- In TA, 'being OK' means 'I accept myself as I am and I accept you as you are'-similar to Carl Rogers' 'unconditional positive regard'.

- The basic unit of interaction and communication is a transaction.

- People need 'strokes,' social stimuli, attention or recognition. Positive strokes are vital for psychological well-being, but a negative stroke is preferable to no stroke at all-a 'neutral stroke'.

- People resist interventions that challenge their world view or reinforcing beliefs even if these are not based on facts.

- Learning to recognise games helps to avoid being drawn into them.

- Sometimes it is necessary to play games, especially at the social level.

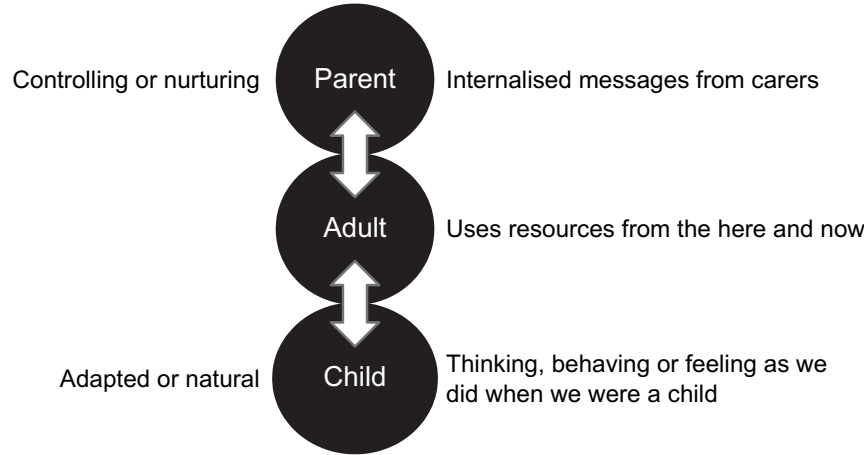

Figure 1 The ego state model.

involves using strategies that worked when we were children (such as compliance or rebelliousness), but which may be inappropriate or unhelpful as adults.

\section{SOCIAL AND PSYCHOLOGICAL 'GAMES'}

Games can be carried out at the social level, when everyone knows what is going on and you can step in and out at will. These include rituals, conversational gambits and pastimes. Social games offer us positive strokes and recognition; when playing these we remain primarily in the adult ego state and they can continue as long as people are willing to engage in them. However, at a more complex level, people play psychological games (often out of conscious awareness) which, while they may have some enjoyable moves, also result in a 'payoff' (a certain type of familiar emotion or feeling) which reinforces negative beliefs and scripts.

A psychological 'game' is the process of doing something with an ulterior motive that:

- is outside adult awareness

- does not become explicit until the participants switch the way they are behaving, and

- results in everyone feeling confused, misunderstood and wanting to blame the other person. ${ }^{7}$

Berne suggested that high level games result in the player ending up in the courtroom, the hospital or the mortuary. While most games that we encounter in the work situation are not such high level, becoming aware of game playing behaviours can be helpful.

\section{USING THE DRAMA AND WINNER'S TRIANGLES}

Two specific TA models can help our understanding and develop ways of working with trainees: the Drama triangle and the Winner's triangle. The Drama triangle was devised by Stephen Karpman in 1968 as a way of analysing psychological games. ${ }^{10}$

He suggests that whenever people play psychological games, they take one of three roles or 'positions': those of persecutor, rescuer or victim (figure 2).

Table 1 summarises the positions in the drama triangle that people may take, the reality for that position, the characteristics of the behaviours, and the ignoring (discounting) of others' or their own capacity to act in the situation. ${ }^{11}$

In the Drama triangle, victims sees themselves as 'not OK,' sometimes seeking a persecutor to put them down and control them, at other times seeking a rescuer who will help them and confirm the belief that they cannot cope on their own. 'I'm useless at exams, I always have been and I know I'll fail, I might as well give up now.' The persecutor is someone who puts others down and belittles them, seeing others as 'not OK': 'Just pull yourself together, of course you won't fail the exam, you need to put 


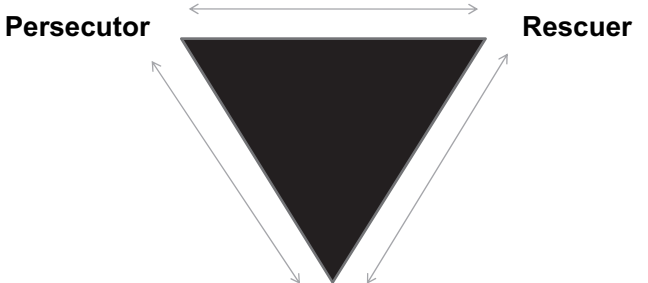

Victim

Figure 2 The Drama triangle. ${ }^{10} 13$

some work in instead of socialising.' The rescuer sees others as being 'not OK', but responds from a one up position in offering help as they do not think others are capable of helping themselves. 'I'll find some sample exam papers for you and we can work together on these every day after work until you feel confident.'

Victim is usually seen as the 'pole position'; it is the one that most often draws someone into a game. When taking these positions, the person is not in the adult ego state, they are responding to and behaving in ways that reflect thoughts, feelings, behaviours from the past rather than the present. All the positions entail a 'discount': the persecutor discounts others' values, dignity and rights; the rescuer discounts others' abilities to think for themselves and be independent; the victim discounts their own ability, and in extreme cases may even discount themselves as a person worthy of attention or regard. We may all find ourselves temporarily taking the Drama triangle positions in the hurly burly of life, at work, at home and in social situations. Although an individual might take a position (due possibly to their own psychological needs), thus potentially 'conning' (drawing in) another person into taking a different position, this does not mean the game will definitely happen. The 'real' game will only happen when there is a 'switch': as the first person switches to another position in the Drama triangle the other person is left confused and frustrated.

Let us consider a real life example to illustrate this.

I was in theatre, with a senior medical student, anaesthetising a patient. I had met only once before. We were discussing fluid management and pain relief and I felt everything was going $O K$. We were in adult to adult interaction working as colleagues. Out of the blue the student just started to tell me about her elective and how she had been raped. I was shocked that this had happened and concerned for her welfare so arranged to talk in my office the next day. During the discussion as details came out, I felt very sorry for her and wanted to help her: I went into rescuer in response to her victim position, but I didn't feel this was inappropriate. I gave her counselling and health advice and felt as if the situation had been dealt with to the best of my ability.

Table 1 Positions in the Drama triangle ${ }^{11}$

\begin{tabular}{|c|c|c|c|}
\hline & Victim & Persecutor & Rescuer \\
\hline Reality & $\begin{array}{l}\text { Suffering or } \\
\text { potentially suffering }\end{array}$ & Act in own interests & $\begin{array}{l}\text { Concern for the } \\
\text { victim }\end{array}$ \\
\hline Characteristics & $\begin{array}{l}\text { Act as if do not have } \\
\text { the resources to } \\
\text { solve their problem } \\
\text { and their need is so } \\
\text { acute that it } \\
\text { prevents them } \\
\text { solving problems. }\end{array}$ & $\begin{array}{l}\text { Others suffer from } \\
\text { their behaviour } \\
\text { Part of goal is to } \\
\text { punish }\end{array}$ & $\begin{array}{l}\text { Take over the } \\
\text { thinking and problem } \\
\text { solving } \\
\text { Do more than their } \\
\text { share } \\
\text { Do things they don't } \\
\text { want to do }\end{array}$ \\
\hline Discount & I can't solve this & $\begin{array}{l}\text { Victim doesn't } \\
\text { matter } \\
\text { I can't be OK unless } \\
\text { you get punished }\end{array}$ & $\begin{array}{l}\text { The victim cannot } \\
\text { solve his/her } \\
\text { problem }\end{array}$ \\
\hline
\end{tabular}

Over next few months she appeared at my office nearly every day to talk, saying that she didn't feel that she could pass her exams. I continued to try to help her as I felt that she needed my support, but began to feel as if nothing I did was good enough and started avoiding her. Eventually she started to complain that I did not have enough time for her. The switch had happened that marks a game, she moved into persecutor and I was now the victim. I realised very slowly that I had been pulled into a game. I felt very naive not to have seen the game developing but it is hard to draw the line between wanting to see the best in people and help them and feeling that you are being punished for something that isn't your fault.

There are a number of ways of not engaging in the Drama triangle. The first is to spot your own and others' potential for game playing so that you remain in adult and do not get drawn into rescuing (the most common position for health professionals in clinical games). This involves staying 'in the moment' (ie, what is happening right now between you and others) and paying attention to feelings and bodily sensations. How many times have we looked at the diary and had a 'heartsink moment' before a meeting with someone? If you find yourself thinking here we go again at any time during an interaction, it is likely that you have spotted a game player or a game. Another way of not engaging in the Drama triangle is by stepping out of the game; this can be after seconds into a transaction or after months of working with someone. Actually being able to say, from adult, $I$ don't feel this discussion/plan/approach is taking us anywhere... or I appreciate how you feel, however, this is what you have to do in order to complete your training can sometimes break the spell. Games can be highly seductive for both players. They can enable players to receive psychological 'payoffs' (usually feeling bad about something or that you have 'won') and thus reinforce deeply held 'script' beliefs about what they deserve, might achieve or get from other people. ${ }^{12}$

So, in the Drama triangle, although as a supervisor the rescuer position might appear appropriate, if it does not enable someone to be truly independent and autonomous, it actually reinforces their own belief that they are a victim or a persecutor. And the longer you stay in any position (or are seen to by the other) then the game goes on. What often happens is that the person feels that they cannot be helped, so all your offers of help somehow do not work out. Then the other switches from victim to persecutor-you said it would work and look what's happened now, it is worse than ever - and you end up feeling misunderstood and at a loss to know what to do next. And so the game goes on.

Acey Choy developed a potential solution to the Drama triangle through the development of the Winner's triangle, (figure 3). ${ }^{13}$ Table 2 summarises the positions in the Winner's triangle.

In the Winner's triangle, the three positions correspond to those in the Drama triangle but with a shift in emphasis to an 'I'm OK-you're OK' position from all players. In the Winner's triangle each person takes responsibility for their position, their actions and their feelings.

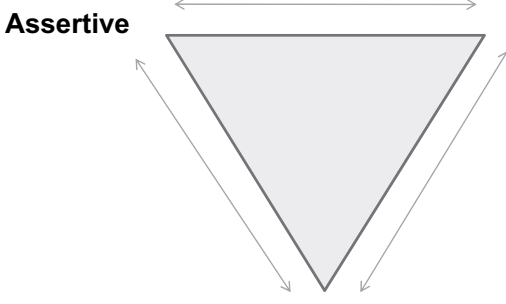

Caring

Figure 3 The Winner's triangle. ${ }^{13}$ 
Table 2 Positions in the Winner's triangle ${ }^{11}$

\begin{tabular}{|c|c|c|c|}
\hline & Vulnerable & Assertive & Caring \\
\hline Reality & Suffering or potentially suffering & Act in own interests & Concern for the vulnerable person \\
\hline Characteristics & $\begin{array}{l}\text { Use adult ego state for thinking and problem solving } \\
\text { Awareness - use their feelings as data for problem solving }\end{array}$ & $\begin{array}{l}\text { Ask for what they want } \\
\text { Say no to what they don't want } \\
\text { Give feedback and initiate negotiation } \\
\text { Make changes in order to get their needs met } \\
\text { Do not punish }\end{array}$ & $\begin{array}{l}\text { Do not do the thinking and problem solving } \\
\text { Do not take over, unless asked (and they want to) } \\
\text { Do not do more than their share } \\
\text { Do not do things they do not want to do }\end{array}$ \\
\hline Skill & Problem solving, self awareness & Assertion skills & Listening skills, self awareness \\
\hline
\end{tabular}

The assertive position reflects the persecutor; however, although the person in this position acts according to their own interests and needs, they use assertive skills (such as negotiation and authentic, honest communication) to get what they want. They do not punish or put down. The rescuer is replaced by the caring position. Here there is real concern for the vulnerable person. Listening skills and self awareness are important to avoid doing things that you do not want to, or take over, think or problem solve for the other. The vulnerable position corresponds with the victim. Although the person in the vulnerable position may be suffering as much as someone in victim, they are able to use their adult ego state for problem solving and thinking, particularly tuning into what their feelings and bodily sensations are telling them about what is going on. This attunement is often a first step of shifting out of a child ego state into adult, which then enables the use of adult resources to help solve problems and find solutions. In our example above, a supervisor coming from a caring position would use listening skills to help the trainee identify their feelings about the situation and think about what might be a useful way forward, rather than (as a rescuer might) discounting feelings, trying to solve the problem for them and doing things that they do not really wish to do.

\section{SOME EXAMPLES}

You are the educational supervisor for a female trainee from overseas. Complaints have been made by the ward staff about her. These involve being 'short' with staff and not turning up on time. You know, from previous meetings, that discussions tend to deteriorate into unclear communications which are not adult-adult. You realise that you have been reinforcing the Drama triangle, as she adopts the victim position (by blaming others for being racist as an explanation of her own responses and behaviours) you oscillate between rescuer and persecutor. It feels that you can never win, say or do the right thing.

You decide to use the Winner's triangle when you talk to her next. Instead of solving the work problem and setting educational objectives and action plans, you adopt the caring position and use listening skills. You find out that the trainee is still living with (and caring for) her elderly sick parents as this is her cultural duty and this is putting great strain on her work. Based on this increased understanding, both of you move into an adult-adult interaction which enables the trainee to work with you to use problem solving skills to negotiate options around more flexible working and access to support.

A final example shows how it is not always others who play games, but we need to be aware of our own potential for game playing and taking positions in the Drama triangle.

\footnotetext{
You overhear two trainees talking in the cafeteria one morning as you are having your morning coffee. Clearly they are discussing their supervisor. One says: "I don't know what is up with him, every time I ask him something he says he is too busy, I make appointments for meetings and he cancels. He hasn't any time for me and I don't know what to do." Her friend replies: "If I were you I would complain, everyone says he shouldn't be a supervisor, I don't know why you put up with him treating you like that".
}

As you finish your coffee, you glance over and realise that the first trainee is your new F2 who has been with you about three months. They don't see you, but as you walk away you start to think about how your behaviour must seem to the trainee. She sees you as persecutor and herself as victim, but you realise that you feel like it is the other way round. You have so many clinical and management responsibilities that you haven't the energy to meet with trainees and discuss their problems. They seem more and more demanding of you and you realise that you need to talk to someone about this as the situation is no good for anyone. The medical director agrees to meet with you the next day and as you recount the story, he suggests that instead of looking at this as a Drama triangle, you think about it in terms of the Winner's triangle instead. His caring approach, skills in listening to what you have to say, and pointing out that you are vulnerable (you are very busy with two sick colleagues and worried that you cannot keep up with all your commitments) rather than a victim, enables you to start thinking about what you might want from the situation and get your needs met. You reflect on this over the next week or so and start to have conversations with colleagues and managers about your own workload and responsibilities.

You arrange to meet with your trainee, and while you do not discuss your personal issues with them, you start to put your relationship back on an adult-adult footing.

\section{CONCLUSION}

We have seen how TA uses simple, accessible models to explain complex situations and interactions which lend themselves to a deeper understanding of everyday communications. The models help us understand the ways in which we can easily be pulled into games and also offers insight into our own behaviours. These models also offer understanding of other relationships, including those with patients, carers and colleagues. We should not assume that games are being played all the time, but the models give us clues as to why some communications seem to appear ineffective and frustrating and offer ways of developing more assertive communications based on adult-adult interactions which can lead to more effective relationships between supervisor and trainee.

\section{Main messages}

- Effective supervision requires clear, open communication from both supervisors and trainees.

- Ideas from transactional analysis (TA), along with other models, can help to improve communications.

- Enhancing awareness of how psychological games might affect the supervision process can help supervisors be more effective.

- The Drama and Winner's triangles offer ideas and solutions for addressing difficult conversations and improving communications. 


\section{Current research questions}

What effect does the use of different models underpinning supervision practice in postgraduate medical education have on trainee outcomes?

- Should faculty development programmes for supervisors include systematic training on how to use and apply models from psychology and psychotherapy, and, if so, which models would be most appropriate?

- What benefits accrue to patients as the result of improved supervision in postgraduate medical education?

Acknowledgements No funding was provided for this article's development. There is no conflict of interest for either of the authors.

Competing interests None

Contributors Both authors made substantial contributions to the planning, writing and reviewing of the article.
Provenance and peer review Not commissioned; externally peer reviewed.

\section{REFERENCES}

1. Halpern H, McKimm J. Supervision. Br J Hosp Med 2009;70:158-61.

2. Kilminster S, Cottrell D, Grant J, et al. AMEE Guide No. 27: effective educational and clinical supervision. Med Teach 2007:29:2-19.

3. Department of Health. A guide to postgraduate speciality training in the UK The Gold Guide. London, HMSO, 2007.

4. Cooper N, Forrest K, eds. Essential guide to educational supervision in postgraduate medical education. London: Wiley Blackwell/BMJ Books, 2009

5. Berne E. Games people play. New York: Grove Press, 1964.

6. Berne E. What do you say after you say hello. New York: Grove Press, 1972

7. Stewart I, Joines V. TA Today: A new introduction to transactional analysis. Nottingham: Russell Press Ltd, 1987 (2005 edition).

8. Hay J. Transactional Analysis for Trainers. Watford UK: Sherwood Publishing, 1996

9. Wyer I. Controlling the consultation III-transactional analysis, first published in Onmedica.com. 2006. http://www.dorsetgp.org.uk/pdf/controlling the_consultation 3.pdf (accessed Oct 2009)

10. Karpman S. Fairy tales and script drama analysis. Transactional Analysis Bulletin 1968; 7:39-43

11. Burgess RC. A model for enhancing individual and organisational learning of 'Emotional Intelligence': the Drama and Winners' Triangles. Soc Work Edu 2005:24:97-112

12. Steiner C. Scripts people live. New York: Grove Press, 1974.

13. Choy A. The Winner's Triangle. Transactional Analysis Journal 1990:20:40-6. 